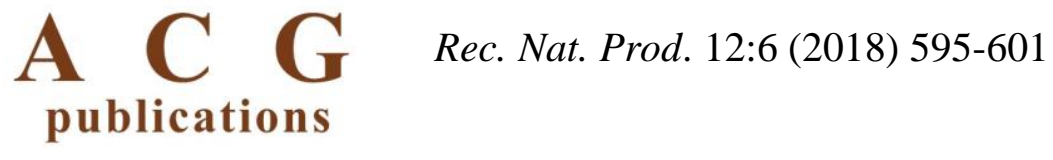

\title{
Evaluating Antiinflammatory and Antiandrogenic Effects of Garden Cress (Lepidium sativum L.) in HaCaT cells
}

\author{
Murat Türkoğlu $^{\oplus 1}$, Songül Kılıç ${ }^{\oplus 1}$, Erkin Pekmezci ${ }^{\oplus 2}$ and \\ Murat Kartal $^{\oplus 3,4^{*}}$ \\ ${ }^{1}$ Biota Laboratories $R \& D$ Center, Sancaktepe, 34785, Istanbul, Türkiye \\ ${ }^{2}$ Gözde Group Hospitals, Dermatology Department, 44100, Malatya, Türkiye \\ ${ }^{3}$ Bezmialem Vakif University, Bezmialem Center of Education, Practice and Research in Phytotherapy, Fatih, \\ 34093, Istanbul, Türkiye \\ ${ }^{4}$ Bezmialem Vaklf University, Faculty of Pharmacy, Department of Pharmacognosy \&Phytochemistry, 34093- \\ Istanbul, Türkiye
}

(Received January 09, 2018; Revised March 05, 2018; Accepted June 08, 2018)

\begin{abstract}
Lepidium sativum L. (Brassicaceae) (Ls), garden cress, is an edible herb that is botanically related to watercress and mustard, sharing their peppery, tangy flavor and aroma. The various parts of the plant have been traditionally used for many respiratory, rheumatologic, cardiovasculary, metabolic, and gastrointestinal disorders. Several studies were performed showing its antiinflammatory, anticarcinogenic, antiproliferative as well as tissue protective effects. In all of these studies the positive effects of Ls were concluded as the result of its antioxidant features due to the polyphenols and organosulphur compounds. In this study, we investigated the molecular basis of antiinflammatory, antiproliferative, antimitotic and antiandrogenic effects of Ls leaf extract in $\mathrm{HaCaT}$ cells. The gene expression levels of vascular endothelial growth factor (VEGF), tumor necrosis factoralpha (TNF- $\alpha$ ), interleukin 1-alpha (IL-1 $\alpha$ ), and 5 alpha-reductase type II (SRD5A2) were studied. Gene expressions were determined by RT-qPCR analysis. Fold change results of the gene expression analyses showed that the plant extract caused statistically significant downregulation of VEGF $(0.2167, p<0.0001)$, TNF- $\alpha$ $(0.4133, \mathrm{p}=0.0262)$, and SRD5A2 (0.0567, $\mathrm{p}<0.0001)$. The fold change for IL-1 $\alpha$ was 0.6900 and this result was not statistically significant $(\mathrm{p}=0.1522)$. These preliminary results may partially explain the clinical success of Ls in the traditional medicine. Considering these results, topical application of Lepidium sativum extract may be beneficial for inflammatory, androgen dependent disorders of the skin.
\end{abstract}

Keywords: Lepidium sativum; garden cress; SRD5A2; TNFa; VEGF. ○ 2018 ACG Publications. All rights reserved.

\section{Introduction}

Lepidium sativum L. Brassicaceae (Ls), garden cress, is an indigenous plant of the Mediterranean basin and has some ethnobotanic uses in the Middle East, West Asia and India. The plant has been traditionally used for respiratory, rheumatologic, cardiovascular metabolic and gastrointestinal disorders [1-3]. The most important phytochemicals responsible for the therapeutic

*Corresponding author: E Mail: pharmmurat@gmail.com

The article was published by ACG Publications 
effects of Brassica vegetables are organosulphur and phenolic compounds [4]. Brassica vegetables contain high amount of glucosinolates which are metabolised to isothiocyanates and later to sulforaphane. These sulphur containing compounds were shown to have important health improving effects [5]. These organosulphur compounds have been shown to perform induction of carcinogen detoxification, inhibition of tumor cell development, free radical scavenging, cell cycle arrest, and induction of apoptosis [3]. Cruciferous vegetables contain glucosinolates from which isothiocyanates are liberated by the enzyme myrosinase. Isothiocyanates protect laboratory animals against chemically-induced cancer through inhibition of phase I enzymes and/or induction of glutathione- $S$ transferase [6]. Flavonoids are phenolic compounds which have significant role in preventing diseases and improving the health of humans [7,8]. The phenolic compounds of Brassicaceae are water soluble molecules which were shown to be potent antioxidants protecting the human body from oxidative stress $[3,4,7]$. In addition to their antiaging and skin protections effects, phenolics have also have attracted attention due to their use in skin care such as dryness, eczema and acne [9]. The plant is also known to contain oleic acid, palmitic acid, stearic acid, imidazole, lepidine, semilepidinoside A and B, beta-carotene, ascorbic acid, and sinapic acid [10]. Lepidium sativum was reported to have bronchodilatator, antihypertensive, diuretic, antiinflammatory, analgesic, antipyretic, antirheumatic, antihyperglycemic, antidiarrheal, antispasmodic, gastroprotective, hepatoprotective and antihyperlipidemic effects in various studies [2,10,11]. Although the general health promoting effects of Ls were documented well, specific studies in dermatology for this plant is lacking. In this study, we investigated the molecular basis of antiinflammatory, antiproliferative, and antimitotic activities of this plant extract. The gene expression levels of vascular endothelial growth factor (VEGF), tumor necrosis factor-alpha (TNF- $\alpha$ ), interleukin 1-alpha (IL-1 $\alpha$ ), and 5 alpha-reductase type II (SRD5A2) were studied in human keratinocyte cells. We also report the results of the analysis of the phenolic compounds of Lepidium sativum L.

\section{Materials and Methods}

\subsection{Preparation of Plant Extract}

The leaves of Lepidium sativum L. were collected from Izmir, Western district of Turkey. They were identified using a stereomicroscope and a guidebook in our research laboratory. $10 \mathrm{~g}$ of fresh leaves were fine cut and extracted with $100 \mathrm{ml}$ distilled water: ethanol (1:1) with a pressure extractor (Timatic Micro, Spello, Italy) for $2 \mathrm{~h}$ at $25^{\circ} \mathrm{C}$ without applying any heat $[12,13]$. The extract was filtered through a $0.45 \mu \mathrm{m}$ filter paper into a sterile bottle for further studies.

\subsection{Phytochemical Analysis of Plant Extract with HPLC System}

The analytical procedure was adapted from the literature with slight changes. The method validation was performed and compared to the original paper before applying the procedure to Lepidium sativum. The details of the procedure of the validation method can be found in the literature [14]. The system was Shimadzu (Japan) UFCL prominence with a SPD-M20A PDA detector and the column was GL Sciences ODS-3 $250 \mathrm{~mm} \times 3 \mathrm{~mm} \times 3 \mu \mathrm{m}$ octadecylsilyl silica gel. System conditions were as follows: Mobile Phase A: Water (1:1000) - phosphoric acid; Mobile Phase B: Acetonitrile; Flow, $0.5 \mathrm{~mL} / \mathrm{min}-1$; Injection Volume, $20 \mu \mathrm{L}$; Column Temperature, $25^{\circ} \mathrm{C}$.

\subsection{Cell Culture}

The human keratinocyte cells (HaCaT) were maintained in Dulbecco's Modified Eagle's medium with high glucose, supplemented with $10 \%$ heat-inactivated fetal bovine serum, $2 \mathrm{mM} \mathrm{l-}$ glutamine and $100 \mathrm{U} / \mathrm{mL}$ gentamicin at $37{ }^{\circ} \mathrm{C}$ in a humidified atmosphere at $5 \% \mathrm{CO}$. (All supplements and media, Sigma Aldrich, USA). 


\subsection{Cell Proliferation Assay}

The Cell Proliferation Kit II was used for cell viability (Roche Diagnostics, Germany). Cells were seeded into 96-well plates $\left(1 \times 10^{4}\right.$ cells/well $)$ and were subjected to different concentrations of plant extract $(1: 1,1: 10,3: 100,1: 100$, and 1:1000) for $72 \mathrm{~h}$. XTT and activator reagents were added to the plates according to the manufacturer's instructions and cells were incubated at same condition. The absorbance was measured at $495 \mathrm{~nm}$ with 650 as a reference wavelength in a microplate reader (BioRad, Japan). Cell survival was measured from the equation:

Cell viability $(\%)=[$ Mean OD of the test group / Mean OD of control group $] \times 100$

\subsection{Reverse Transcription}

HaCaT cells were incubated for 3 days with $10 \%$ concentration of thermal waters before total RNA isolation. TRI reagent (Sigma Aldrich) was used for RNA isolation. The concentration and purity of isolated RNA samples were determined using BioSpec-nano (Japan). Transcriptor First Strand cDNA Synthesis Kit was used for reverse transcriptase (Roche Molecular Diagnostics, Germany). Total volume of reaction mixture was $13 \mu$ l containing $1 \mu \mathrm{g}$ total RNA, $2 \mu \mathrm{M}$ sequencespecific primer and water. The mixture was heated for $10 \mathrm{~min}$ at $65^{\circ} \mathrm{C}$. The mixture volume was completed to $20 \mu \mathrm{l}$ by adding $10 \mathrm{U}$ of transcriptor reverse transcriptase, $20 \mathrm{U}$ of protector RNase inhibitor, $1 \mathrm{X}$ buffer and $1 \mathrm{mM}$ deoxy nucleotide and the mixture incubated at $50{ }^{\circ} \mathrm{C}$ for $60 \mathrm{~min}$ and then $85^{\circ} \mathrm{C}$ for $5 \mathrm{~min}$.

\subsection{Real-Time Quantitative Polymerase Chain Reaction}

The experiments were conducted with Light Cycler 96 (Roche Diagnostics, USA) and Fast Start DNA Green Master Kit (Roche Molecular Diagnostics, Germany). Each $20 \mu \mathrm{L}$ reaction contained 10 $\mu \mathrm{L}$ SYBR Green Master Mix (2X), $0.5 \mu \mathrm{M}$ of reverse and forward primers (Table 1), $2.5 \mathrm{ng}$ cDNA and appropriate amount of nuclease free water. All samples were run as triplicates in each run including a non-template control and four standards (1:10, 1:100 and 1:1000). All reactions subjected to initial denaturation step at $95^{\circ} \mathrm{C}$ for $10 \mathrm{~min}$ and 45 cycle of 3-step amplification. Melting curve analysis was performed to confirm specificity the amplified products. PCR reaction was carried out in triplicate. For quantitation of RT-qPCR results, $\Delta \Delta \mathrm{Ct}$ method was used.

Table 1. Primers (5' - 3') of the genes studied.

\begin{tabular}{lll}
\hline Primers & Forward primer & Reverse primer \\
\hline GAPDH $^{\S}$ & ATGGGTGTGAACCATGAGAA & GTGCTAAGCAGTTGGTGGTG \\
VEGF & ATGCGGATCAAACCTCACCA & CCACAGGGACGGGATTTCTTG \\
TNF- $\alpha$ & CCTGCTGCACTTTGGAGTGA & GAGGGTTTGCTACAACATGGG \\
IL-1 $\alpha$ & ACCAGTGCTGCTGAAGGAGAT & GTGCCGTGAGTTTCCCAGAA \\
SRD5A2 & CGCTCTACCAGTACGCCAG & AATTAAGCACCGATGCCCGT \\
\hline
\end{tabular}

${ }^{\S}$ Glyceraldehyde-3-phosphate dehydrogenase used as control

\subsection{Statistical Analysis}

All data are representative of three experiments and expressed as mean \pm standard deviation. Statistical evaluation was performed by non-parametric Mann-Whitney test and statistical significance was defined as $\mathrm{p}<0.05$.

\section{Results and Discussion}

\subsection{Phytochemical Analysis}

The phenolic compounds found by the HPLC analysis of Lepidium sativum extract were given in Table 2. Ferulic acid concentration was the highest among measured phenolics. 
Table 2. Phenolic compounds identified in Lepidium sativum leaves

\begin{tabular}{llllll}
\hline Fumaric acid & Gallic acid & Ferulic acid & Sinapic acid & Malic acid & $\begin{array}{l}\text { Caffeoylmalic } \\
\text { acid }\end{array}$ \\
\hline $32 \mu \mathrm{g} / \mathrm{mL}$ & $2.0 \mu \mathrm{g} / \mathrm{mL}$ & $945 \mu \mathrm{g} / \mathrm{mL}$ & $41 \mu \mathrm{g} / \mathrm{mL}$ & $102 \mu \mathrm{g} / \mathrm{mL}$ & $3 \mu \mathrm{g} / \mathrm{mL}$ \\
\hline
\end{tabular}

\subsection{Cytotoxicity Results}

Higher concentrations were found to be cytotoxic for HaCaT cells. For the subsequent analysis, the possible highest concentration was determined as 5\% and $\mathrm{HaCaT}$ cells were incubated with 5\% plant extract extract before total RNA isolation (Figure 1).

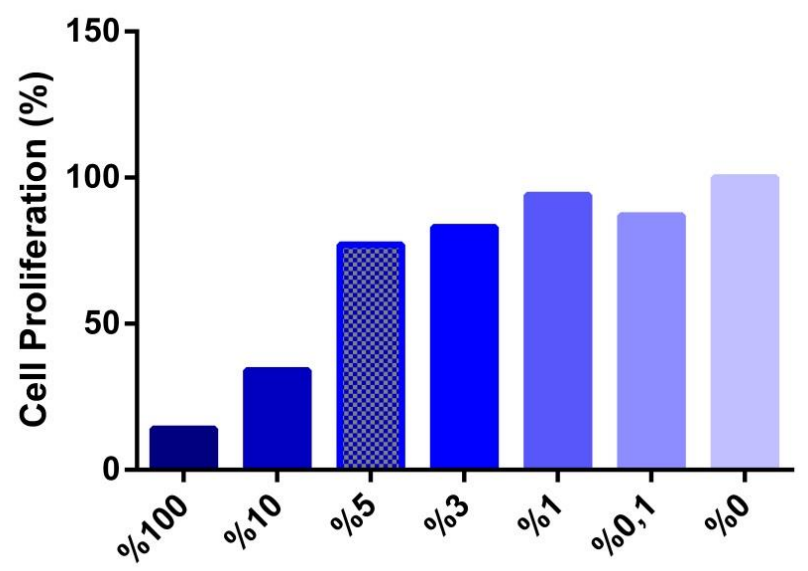

Figure 1. Cytotoxicity analysis result of Lepidium sativum extract*.

*The dashed bar represents the extract concentration chosen for incubation

\subsection{Gene Expression Analysis (Real-Time qPCR)}

Results of gene expression analyses via RT-qPCR were provided in Figure 2. Plant extract caused statistically significant downregulation of VEGF $(p<0.0001)$, TNF- $\alpha(p=0.0262)$, and SRD5A2 $(\mathrm{p}<0.0001)$ gene expressions, compared to untreated control cells. Plant extract treatment ended up with $0.2167,0.4133$, and 0.0567 fold changes for VEGF, TNF- $\alpha$ and SRD5A2 respectively (Table 3).

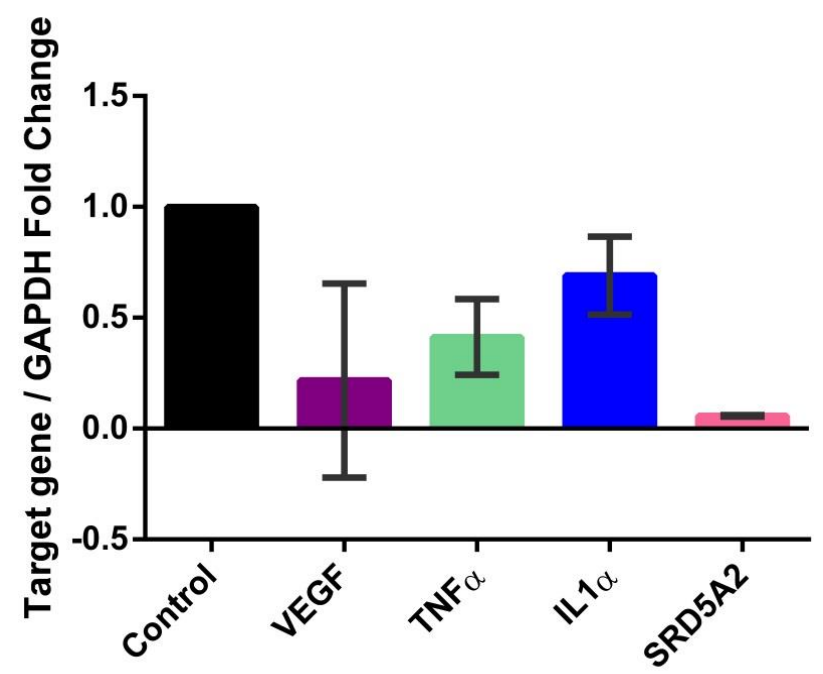

Figure 2. Expression levels of the selected genes 
Table 3. Fold changes of the genes obtained by the treatment of HaCaT cells with plant extract.

\begin{tabular}{lll}
\hline Gene & Fold change & p value \\
\hline VEGF & $0.2167 \pm 0.4372$ & $<0.0001$ \\
TNF- $\alpha$ & $0.4133 \pm 0.1703$ & $=0.0262$ \\
IL-1 $\alpha$ & $0.6900 \pm 0.1756$ & $=0.1522$ \\
SRD5A2 & $0.0567 \pm 0.0033$ & $<0.0001$ \\
\hline
\end{tabular}

Although the in vitro and in vivo studies performed with various Ls extracts showed this plant's beneficial effects to human health for many clinical entities, mostly the exact mechanism of these positive results still remain obscure. Some of the phenolic compounds detected in our extract were not reported previously (Table 2). Among the polyphenols found in our extract, efficacy of fumaric acid was depicted in psoriasis $[15,16]$. In various clinical studies ferulic acid was found to have protective effects against damage caused by the UV irradiation and chemically induced skin tumorigenesis [1719]. Ferulic acid and sinapic acid analogues were reported to inhibit UVA induced oxidative stress in skin [20]. Malic acid was shown to have antihyperpigmentation effects [21]. Gallic acid, one of the most extensively studied polyphenol, has been reported to have various actions in the skin such as depigmentation, induction of apoptosis in melanoma cells [22-24]. VEGF is an angiogenic factor and several anti-VEGF therapies are being used in the treatment of diseases characterised by abnormal blood vessel formation [25]. VEGF is important in regulation of the immunological response and has activity in immediate and delayed type hypersensitivity [26] as well as some acute inflammatory skin disorders like urticaria and UV-B induced damage [27]. TNF, although discovered as a result of its antitumor activity in the beginning, has now been found having functions in tumor initiation, progression, and metastasis [28]. TNF- $\alpha$, synthesized in epidermal keratinocytes was shown to be a very potent inhibitor of follicle proliferation and plays a major role in the pathogenesis of alopecia areata (AA) [29]. Intradermal injection of TNF- $\alpha$ caused a significant high number of apoptotic cells in the epidermis [30]. In AA patients with active hair loss, mRNA expression of TNF- $\alpha$ was detected higher in deep dermis than upper dermis and it was also in accordance with the activity of the disease [31]. IL-1 is more closely related to TNF than any other cytokine, although the structure and receptors for IL-1 and TNF are evidently different [32]. Also these two cytokines were thought to have important functions in the pathogenesis of acne [33]. 5 alpha-reductase isozymes are extensively expressed in human tissues. This enzyme family includes three members that realize various functions in androgen stimulated skin disorders such as androgenetic alopecia (AGA), acne and hirsutism [34, 35]. Lepidium sativum L. leaf extract causing the downregulation of the gene expressions of main angiogenic, inflammatory and androgenic molecules in HaCaT cells, offers a wide array of opportunities for in vivo investigation to detect its efficacy in various skin diseases. Although there may be many other mechanisms of action to be depicted on the molecular basis, considering together the described skin effects of the detected polyphenols and the demonstrated molecular mechanisms of action in $\mathrm{HaCaT}$ cells, these preliminary results may partially explain the clinical success of Ls in the traditional medicine.

\section{Conclusion}

In the light of these results, it was our hypothesis that the topical Lepidium sativum L. leaf extract may be beneficial for some non-invasive skin tumors such as certain hemangiomas and inflammatory disorders such as psoriasis, atopic dermatitis, and alopecia areata. The hyperpigmentation disorders such as melasma and some androgen dependent diseases such as acne and androgenetic alopecia.

\section{ORCID ID}

Murat Türkoğlu: 0000-0003-4111-2642

Songül Kılıç: 0000-0001-5299-712X

Erkin Pekmezci: 0000-0003-1469-2557 
Murat Kartal: 0000-0003-3538-2769

\section{References}

[1] N. D. Raval and T. N. Pandya (2011). Pharmacognostic study of Lepidium sativum L. (Chandrashura), Ауи. 32(1), 116-119.

[2] M. Sakran, Y. Selim and N. Zidan (2014). A new isoflavonoid from seeds of Lepidium sativum L. and its protective effect on hepatotoxicity induced by paracetamol in male rats, Molecules 19(10), 15440-15451.

[3] S. H. Mahassni and R. M. Al-Reemi (2013). Apoptosis and necrosis of human breast cancer cells by an aqueous extract of garden cress (Lepidium sativum) seeds, Saudi J. Biol. Sci. 20(2), 131-139.

[4] I. Sharma, M. Aaradhya, M. Kodikonda and P. R. Naik (2015). Antihyperglycemic, antihyperlipidemic and antioxidant activity of phenolic rich extract of Brassica oleraceae var gongylodes on streptozotocin induced Wistar rats, SpringerPlus 4(1), 212.

[5] M. S. Hifnawy, R. M Salam, M. A. Rabeh and M. A. Aboseada (2013). Glucosinolates, glycosidically bound volatiles and antimicrobial activity of Brassica oleraceae var. botrytis, (soultany cultivar), Arch. Biochem. Biophys. 3, 66-81.

[6] F. Kassie, S. Rabot, M. Uhl, W. Huber, H.M. Qin, C. Helma, R. Schulte-Hermann and S. Knasmüller (2002). Chemoprotective effects of garden cress (Lepidium sativum) and its constituents towards 2amino-3-methyl-imidazo [4, 5-f] quinoline (IQ)-induced genotoxic effects and colonic preneoplastic lesions, Carcinogenesis 23(7), 1155-1161.

[7] A. A. Shad, S. Ahmad, R. Ullah, N. M. AbdEl-Salam, H. Fouad, N. U. Rehman, H. Hussain and W. Saeed (2014). Phytochemical and biological activities of four wild medicinal plants, The Sci. World. J. 2014

[8] T. Eteraf-Oskouei, S. Allahyari, A Akbarzadeh-Atashkhosrow, A. Delazar, M. Pashaii, S.H. Gan and M. Najafi (2015). Methanolic extract of Ficus carica L. leaves exerts antiangiogenesis effects based on the rat air pouch model of inflammation, Evid. Based Complement. Altern. Med. 2015, 760405, 9 pages .http://dx.doi.org/10.1155/2015/760405

[9] T. Aburjai and F.M. Natsheh (2003). Plants used in cosmetics, Phytother. Res. 17(9), 987-1000.

[10] N.U. Rehman, A.U. Khan, K.M. Alkharfy and A.H. Gilani (2012). Pharmacological basis for the medicinal use of Lepidium sativum in airways disorders, Evid. Based Complement. Alternat. Med. 2012, 596524. 8 pages http://dx.doi.org/10.1155/2012/596524

[11] M.A. Al-Yahya, J.S. Mossa, A.M Ageel and S. Rafatullah (1994). Pharmacological and safety evaluation studies on Lepidium sativum L., seeds, Phytomed. 1(2), 155-159.

[12] N.S. Ncube, A.J. Afolayan and A.I. Okoh (2008). Assessment techniques of antimicrobial properties of natural compounds of plant origin: current methods and future trends, Afr. J. Biotechnol. 7(12),17971806.

[13] N.N. Azwanida (2015). A review on the extraction methods use in medicinal plants, principle, strength and limitation, Med. Aroma.t Plants 4(196), 2167-0412.

[14] P. Mattila and J. Kumpulainen (2002). Determination of free and total phenolic acids in plant-derived foods by HPLC with diode-array detection, J. Agriv. Food Chem. 50(13), 3660-3667.

[15] A. M. Saracino and C. H. Orteu (2017). Severe recalcitrant cutaneous manifestations in systemic lupus erythematosus successfully treated with fumaric acid esters, Br. J. Dermatol. 176(2), 472-480.

[16] J. Zweegers, M. E. Otero, J. M. van den Reek, P. P. van Lümig, R. J. Driessen, W. Kievit, M. Seyger, P. van de Kerkhof and E. Jong (2016). Effectiveness of biologic and conventional systemic therapies in adults with chronic plaque psoriasis in daily practice: a systematic review, Acta Dermatol. Venereol. 96(4), 453-458.

[17] J. C. Murray, J. A. Burch, R. D. Streilein, M. A. Iannacchione, R. P. Hall and S. R. Pinnell (2008). A topical antioxidant solution containing vitamins $\mathrm{C}$ and $\mathrm{E}$ stabilized by ferulic acid provides protection for human skin against damage caused by ultraviolet irradiation, J.Am. Acad. Dermatol. 59(3), 418-425.

[18] J. Y. Lin, J. A. Tournas, J. A. Burch, N. A. Monteiro-Riviere and J. Zielinski (2008). Topical isoflavones provide effective photoprotection to skin, Photodermatol. Photoimmunol. Photomed. 24(2), 61-66.

[19] A. Kaul and L. Khanduja (1998). Polyphenols inhibit promotional phase of tumorigenesis: relevance of superoxide radicals, Nutr. Cancer. 32(2), 81-85.

[20] J. P. Ley (2001). Phenolic acid amides of phenolic benzylamines against UVA induced oxidative stress in skin, Int. J. Cosmet. Sci. 23(1), 35-48.

[21] M. B. Taylor, J. S. Yanaki, D. O. Draper, J. C. Shurtz and M. Coglianese (2013). Successful short-term and long-term treatment of melasma and postinflammatory hyperpigmentation using vitamin $\mathrm{C}$ with a full-face iontophoresis mask and a mandelic/malic acid skin care regimen, J. Drugs Dermatol. 12(1), 4550 . 
[22] K. J. Kumar, M. G. Vani, S. Y. Wang, J. W. Liao, L. S. Hsu, H. L. Yang and Y. C. Hseu (2013). In vitro and in vivo studies disclosed the depigmenting effects of gallic acid: A novel skin lightening agent for hyperpigmentary skin diseases, Biofactors. 39(3), 259-270.

[23] C. Liu, J.J. Lin, Z. Y. Yang, C. C. Tsai, J. L. Hsu and Y. J Wu (2014). Proteomic study reveals a cooccurrence of gallic acid-induced apoptosis and glycolysis in B16F10 melanoma cells, J. Agric. Food Chem. 62(48), 11672-11680.

[24] V. Subramanian, B. Venkatesan, A. Tumala and E. Vellaichamy (2014). Topical application of Gallic acid suppresses the 7, 12-DMBA/Croton oil induced two-step skin carcinogenesis by modulating antioxidants and MMP-2/MMP-9 in Swiss albino mice, Food Chem. Toxicol. 66, 44-55.

[25] M. Canavese, F. Altruda, T. Ruzicka and J. Schauber (2010). Vascular endothelial growth factor (VEGF) in the pathogenesis of psoriasis - a possible target for novel therapies?, J.Dermatolog. Sci. 58(3), 171176.

[26] E. Koczy-Baron and A. Kasperska-Zając (2014). The role of vascular endothelial growth factor in inflammatory processes, Postepy. Hig. Med. Dosw. 68, 57-65.

[27] G. Varricchi, F. Granata, S. Loffredo, A. Genovese and G. Marone (2015). Angiogenesis and lymphangiogenesis in inflammatory skin disorders, J. Am. Academ. Dermatol. 73(1), 144-153.

[28] B. B. Aggarwal, S. Shishodia, Y. Takada, D. Jackson-Bernitsas, K.S. Ahn, G. Sethi and H. Ichikawa (2006). TNF blockade: an inflammatory issue, Ernst Schering Res. Found. Workshop. (56), 161-186

[29] S. Gregoriou, D. Papafragkaki, G. Kontochristopoulos, E. Rallis, D. Kalogeromitros and D. Rigopoulos (2010). Cytokines and other mediators in alopecia areata, Mediators of Inflamm. 11, 2010.

[30] R. Rückert, G. Lindner, S. Bulfone-Paus and R. Paus (2000). High-dose proinflammatory cytokines induce apoptosis of hair bulb keratinocytes in vivo, Br. J. Dermatol. 143(5), 1036-1039.

[31] C.A. Dinarello (1994). The biological properties of interleukin-1, Eur. Cytokine Network. 5(6):517-531.

[32] L. Li, Y. Wu, Y. F. Cai, L. Geng, X. H. Gao and H. D. Chen (2015). The tumour necrosis factor- $\alpha$ 308G> A genetic polymorphism may contribute to the pathogenesis of acne: a meta-analysis, Clin. Exp. Dermatol. 40(6), 682-687.

[33] Y. S. Yang, H. K. Lim, K. K. Hong, M. K. Shin, J. W. Lee, S. W. Lee and N. I. Kim (2014). Cigarette smoke-induced interleukin-1 alpha may be involved in the pathogenesis of adult acne, Ann. Dermatol. 26(1), 11-16.

[34] F. Azzouni, N. Zeitouni and J. Mohler (2013). Role of 5 $\alpha$-reductase inhibitors in androgen-stimulated skin disorders, J. Drugs Dermatol. 12(2), e30.

[35] M. G. Mercurio and D. S. Gogstetter (2000). Androgen physiology and the cutaneous pilosebaceous unit, The J. Gend. Specific Med. 3(4), 59-64.

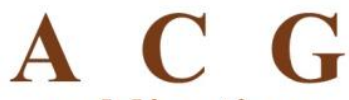

publications

(C) 2018 ACG Publications 